\title{
Factors influencing the contribution of ion-induced nucleation in a boreal forest, Finland
}

\author{
S. Gagné ${ }^{1}$, T. Nieminen ${ }^{1}$, T. Kurtén ${ }^{1,2}$, H. E. Manninen ${ }^{1}$, T. Petäjä ${ }^{1}$, L. Laakso ${ }^{1,3}$, V.-M. Kerminen ${ }^{1,4}$, M. Boy ${ }^{1}$, and \\ M. Kulmala ${ }^{1,5}$ \\ ${ }^{1}$ Department of Physics, P.O. Box 64, University of Helsinki, 00014 Helsinki, Finland \\ ${ }^{2}$ Department of Chemistry, University of Copenhagen, 2100 Copenhagen, Denmark \\ ${ }^{3}$ School of Physical and Chemical Sciences, North-West University, Private Bag x6001, Potchefstroom 2520, South Africa \\ ${ }^{4}$ Finnish Meteorological Institute, P.O. Box 503, 00101 Helsinki, Finland \\ ${ }^{5}$ Department of Applied Environmental Science, Stockholm University, 10691 Stockholm, Sweden
}

Received: 11 November 2009 - Published in Atmos. Chem. Phys. Discuss.: 1 December 2009

Revised: 1 April 2010 - Accepted: 7 April 2010 - Published: 21 April 2010

\begin{abstract}
We present the longest series of measurements so far ( 2 years and 7 months) made with an Ion-DMPS at the SMEAR II measurement station in Hyytiälä, Southern Finland. We show that the classification into overcharged (implying some participation of ion-induced nucleation) and undercharged (implying no or very little participation of ion-induced nucleation) days, based on Ion-DMPS measurements, agrees with the fraction of ion-induced nucleation based on NAIS measurements. Those classes are based on the ratio of ambient charged particle to steady-state charged particle concentration, known as the charging state. We analyzed the influence of different parameters on the contribution of ion-induced nucleation to the total particle formation rate. We found that the fraction of ion-induced nucleation is typically higher on warmer, drier and sunnier days compared to colder days with less solar radiation and a higher relative humidity. Also, we observed that bigger concentrations of new particles were produced on days with a smaller fraction of ion-induced nucleation. Moreover, sulfuric acid saturation ratios were smaller for days with a bigger fraction of ioninduced nucleation. Finally, we propose explanations on how these different parameters could influence neutral and ioninduced nucleation, and show that the different mechanisms seem to take place at the same time during an event. For example, we propose that these observed differences could be due to high temperature and low vapors' saturation ratios
\end{abstract}

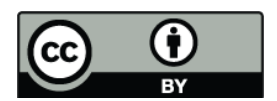

Correspondence to: S. Gagné (stephanie.gagne@ helsinki.fi) (water and sulfuric acid) increasing the height of the energy barrier a particle has to reach before it can grow and thus limiting neutral nucleation.

\section{Introduction}

Atmospheric aerosol particles influence the Earth's radiation balance and hydrological cycle through both direct and indirect effects. The direct effect is due to scattering and absorption of solar radiation by atmospheric aerosol particles (e.g. Myhre et al., 2009) whereas the indirect effects refer to aerosol-related changes in cloud albedo, lifetime and precipitation patterns (e.g. Twomey, 1991; Lohmann and Feichter, 2005; Stevens and Feingold, 2009). The population of aerosol particles capable of affecting cloud properties is called cloud condensation nuclei (CCN). In the atmosphere, $\mathrm{CCN}$ originate from both primary particle emissions and secondary atmospheric production, i.e. the formation of new aerosol particles by nucleation and their subsequent growth to CCN sizes (Andreae and Rosenfeld, 2008). Globally, the contribution of nucleated particles to $\mathrm{CCN}$ populations is estimated to be around $55 \%$ of which $10 \%$ comes from the boundary layer (Spracklen et al., 2008; Merikanto et al., 2009).

Atmospheric new particle formation (NPF) and growth has been observed frequently and in many environments (see Kulmala et al., 2004; Kulmala and Kerminen, 2008; and references therein). The exact mechanisms for nucleation and their relative contribution to new particle formation are not

Published by Copernicus Publications on behalf of the European Geosciences Union. 
well known. Many mechanisms have been proposed (Kulmala, 2003; Yu and Turco, 2001) amongst others: homogeneous (binary and ternary) and heterogeneous (neutral and ion-induced) nucleation. The contribution of ion-induced nucleation - nucleation around a charged kernel - to particle formation is not clearly known: Iida et al. (2008) reported a contribution of less than $1 \%$ in a heavily polluted environment in Mexico city whereas Gagné et al. (2008) reported a median contribution of around $6 \%$ in a relatively clean background environment in Hyytiälä, Finland. Studies including the ion-ion recombination contribution to neutral clusters include that by Yu and Turco (2008), who report almost 100\% of ion-mediated nucleation in Hyytiälä whereas Kulmala et al. (2007) and Manninen et al. (2009a) both reported values around $10 \%$ for the same location. The results of Iida et al. (2006) and Gagné et al. (2008), based on similar measurement and analysis methods, indicate that the contribution of ion-induced nucleation on new particle formation varies from place to place and day to day. Based on measurements in Hyytiälä, Finland, Boy et al., 2008 estimated the contribution of ion-induced nucleation to $3-10 \mathrm{~nm}$ particles in the boundary layer to be up to $15 \%$.

Due to clearly documented varying contribution of ioninduced nucleation on NPF (Laakso et al., 2007a, 2008; Gagné et al., 2008) and an extensive set of measurement, Hyytiälä is a good place to investigate reasons behind these variations. The Ion-DMPS (Ion Differential Mobility Particle Sizer, Laakso et al., 2007a) gives information about the charging state and therefore the contribution of ion-induced and neutral nucleation. It has been operating at the SMEAR II measurement station (Vesala et al., 1998; Hari and Kulmala, 2005), in Hyytiälä, since April 2005 with 246 nucleation events observed until the end of 2007. The Ion-DMPS measures the charging state of a particle population. Comparing the neutralized and the ambient size distributions reveals whether a nucleation event is overcharged (higher concentrations in the ambient sample than in the neutralized sample) or undercharged (higher concentrations in the neutralized sample than in the ambient sample). The charging state (over- or undercharging) gives us information about the participation of ion-induced nucleation in new particle formation and growth (Kerminen et al., 2007). Overcharged new particle formation events suggest (at least) some contribution of ion-induced nucleation and undercharged events suggest no or very little participation of ion-induced nucleation in the new particle formation process.

In this study, we aim to shed new light on factors affecting the contribution of ion-induced nucleation to the total nucleation rate. We start our analysis by demonstrating that the charging state, as measured by the Ion-DMPS, is able to distinguish between particle formation events with a low and a higher contribution by ion-induced nucleation (calculations according to Kulmala et al., 2007a). After this we present the longest time series of particle charging state measurements conducted so far and aim to address the following two questions: (1) how is the contribution of ion-induced nucleation dependent on the season, various meteorological parameters, concentration of electrically charged nanoparticles (i.e. air ions), and the concentration and temporal evolution of the gaseous sulfuric acid concentration? (2) are the different nucleation events characterized by either ion-induced or neutral nucleation, or do these two nucleation pathways occur simultaneously? Finally, we suggest a hypothesis to explain the reasons behind the variation in the proportion of ion-induced nucleation from one day to another.

\section{Materials and methods}

\subsection{Measurements}

This work is based on Ion-DMPS measurements from the SMEAR II station, between April 2005 and December 2007. The station is situated in Hyytiälä, southern Finland $\left(61^{\circ} 51 \mathrm{~N}, 24^{\circ} 17 \mathrm{E}, 181 \mathrm{~m}\right.$ a.s.l.), in a Scots pine boreal forest (Hari and Kulmala, 2005). In this study, we use data from other parameters measured at the same station at various heights in a measurement tower, or at ground level.

\subsubsection{Ion-DMPS}

The Ion-DMPS (Mäkelä et al., 2003; Laakso et al., 2007a) is based on a Differential Mobility Particle Sizer (DMPS, Hoppel, 1987; Aalto et al., 2004) whose bi-polar charger (Ni-63, $370 \mathrm{Mbq}$, half-life of ca. 100 years) can be switched on and off and whose Differential Mobility Analyzer (DMA, Winklmayer et al., 1991) can classify particles of positive and negative polarity according to their electrical mobility. The size range covered was from $3.0 \mathrm{~nm}$ to $15 \mathrm{~nm}$ mobility equivalent diameter between April 2005 until mid December 2006 and from $2.0 \mathrm{~nm}$ to $11.5 \mathrm{~nm}$ after that. The Ion-DMPS can thus work in four modes: it can measure either ambient air ions (neutralizer off) or neutralized air ions (neutralizer on, at electrical charge steady-state), and they both can be measured in either positive or negative mode by changing the polarity of the voltage applied in the DMA. Comparing the ambient and neutralized mode for each polarity gives us the charging state (similar measurements were done by lida et al., 2006, 2008; Vana et al., 2006). The charging state is defined as the ratio of the ambient charged particle concentration to its corresponding neutralized (charge steadystate) concentration. Hence the charging state is the ratio of the fraction of charged particles in the ambient sample to the fraction of charged particles in the neutralized sample. When the value of the charging state is larger than one (i.e. when there are more charged particles in the ambient air than there are at the steady-state), the particle population is said to be overcharged. Oppositely, when it is smaller than one (i.e. when there are fewer charged particles in the ambient air than there are at the steady-state), the particle population is said to be undercharged. Alternatively, if it stays 
around one, the particle population is said to be at the steadystate charging. The particle formation and growth events are classified as overcharged, steady-state and undercharged days independently for each polarity. In this study, we used overcharged and undercharged categories to investigate the reasons behind this difference.

\subsubsection{BSMA}

The Balanced Scanning Mobility Analyzer (BSMA, Tammet 2006) measures the size distribution of naturally charged particles between mobilities of 0.032 to $3.2 \mathrm{~cm}^{2} \mathrm{~V}^{-1} \mathrm{~s}^{-1}$ which correspond to a diameter range of about 0.42 to $7.5 \mathrm{~nm}$ using the algorithm described by Tammet $(1995,1998)$. The BSMA consists of two plain aspiration-type DMAs, one for each polarity, with a common collector electrode. Size segregation is obtained by discharging a capacitor through the repelling electrode and concentration by monitoring the electrometer current in the balanced bridge circuit. The sheath air and the sample air are aspired through parallel plates connected to a high voltage or grounded. The sample and the offset mode alternate by applying a potential difference on the sampling plates. The BSMA has been measuring in Hyytiälä since March 2003 and samples air at about $2 \mathrm{~m}$ above the ground level at a flow rate of about $221 \mathrm{~s}^{-1}$. In this paper, the BSMA is used to retrieve concentration of small and intermediate air ions $(0.4-1.8$ and $1.8-7.5 \mathrm{~nm}$ respectively, in Tammet diameters).

\subsubsection{DMPS}

The Twin-Differential Mobility Particle Sizer (Twin-DMPS, Aalto et al., 2004) is a well established instrument in aerosol research. It measures the size distribution of aerosol particles in time. It is composed of two DMPSs, one for smaller sizes and another for larger sizes. The inlet and the neutralizer are common to both systems. The smaller system measures particles of smaller diameters with a Hauke type DMA $(10.9 \mathrm{~cm}$, Winklmayer et al., 1991) and a TSI 3025 CPC (Stolzenburg and McMurry, 1991). The other one measures particles of larger diameters with a $28 \mathrm{~cm}$ Hauke-type DMA and a TSI 3010 CPC (Mertes et al., 1995). The overall size range is between 3 and $1000 \mathrm{~nm}$ and the measurements are taken at about $8 \mathrm{~m}$ above the ground level. The total (charged and neutral) particle concentration is then calculated assuming charge steady-state after the air sample has been neutralized. In this paper, the DMPS data is used for its total particle concentration.

\subsubsection{NAIS}

The NAIS (Neutral cluster and Air Ion Spectrometer, Kulmala et al., 2007; Manninen et al., 2009b) is an instrument based on the AIS (Air Ion Spectrometer, Mirme et al., 2007) and the airborne version of the NAIS is described by Mirme et al. (2010). It measures the mobility distribution of both negatively and positively charged particles between 3.16 and $0.0013 \mathrm{~cm}^{2} \mathrm{~V}^{-1} \mathrm{~s}^{-1}(0.8$ and $42 \mathrm{~nm}$, in Millikan diameter), and neutral particles between $\sim 2.0$ and $42 \mathrm{~nm}$ in particle size. It consists of two cylindrical DMAs with 21 insulated electrometers each. This allows to the simultaneous measurement of 21 channels of mobility and two polarities, saving time by not having to scan the mobility. It alternates between the charged and neutral modes. In Hyytiälä, this instrument samples at about $2 \mathrm{~m}$ above the ground level. During the period covered in this study, the NAIS was in operation between 6 March and 16 May 2006, between 14 September and 15 December 2006 and between 8 March and $27 \mathrm{Au}-$ gust 2007 (Manninen et al., 2009b).

\subsubsection{Meteorological data}

The meteorological data such as temperature, relative humidity and water vapor concentration are measured in a measurement tower, located at approximately $50 \mathrm{~m}$ away from the particle instruments (Vesala et al., 1998). The data is taken primarily from sensors at $4.2 \mathrm{~m}$ above the ground and from higher levels $(8.4,16.8,33.6,50.4$ and $67.2 \mathrm{~m}$, in priority order) when the main level's data is unavailable.

\subsubsection{Radon ionization and external radiation}

The ion pair production rate is examined based on the direct method described in an earlier study by Laakso et al. (2004). The same instruments were used and the same calculation technique was applied. The ion pair production rate caused by ${ }^{222} \mathrm{Rn}$ is calculated by considering the total energy of three alpha and two beta particles, and assuming that the average ion pair production energy is $34 \mathrm{eV}$. The air is monitored continuously by counting emission of particle-bound radon daughter nuclides collected on fiber-glass filters. The proportion of ${ }^{222} \mathrm{Rn}$ and ${ }^{220} \mathrm{Rn}$ can be distinguished using their half-life differences (Paatero et al., 1998). The uncertainty of the ion pair production rate varies from 3 to $20 \%$ depending on the radon activity concentration.

External radiations, consisting mainly of cosmic radiation and gamma radiation were measured with a scintillation gamma spectrometer. The spectrometer was located at $1.5 \mathrm{~m}$ above the ground. The dose rate is calculated using a calibration factor for an integrated energy spectrum between 100 and $3000 \mathrm{keV}$. The ion pair production rate is obtained by assuming that the average ion pair production energy is $34 \mathrm{eV}$. The uncertainty on the ionization rate is about $\pm 10 \%$. The external radiation is strongly affected by snow cover, indicating that the radiation coming from the ground is playing an important role (Hatakka et al., 1998). It was found that the snow cover and the water content are both influencing the ion pair production rate due to the external radiation, especially if the water is located in the upper layer. 


\subsection{Data analysis}

\subsubsection{Data classification}

All the days between the 1 April 2005 and the 31 December 2007 when the Ion-DMPS was measuring were classified and used in this study. Each day was classified as a NPF event day, undefined day, not an event day or bad/no data, loosely based on the classification of Dal Maso et al. (2005). Event days were those when formation of $3-5 \mathrm{~nm}$ particles and their subsequent growth was observed. Non-event days were those when no formation and growth of new particles was observed. Undefined days were those that did not belong either to the event or the non-event class (e.g. either no growth, or no new particle formation was observed). The last class, called bad/no data took the days when the instrument was not working properly. Of these classified days, only the NPF event days were kept for analysis (event class). The NPF event days were subsequently classified into three subcategories: overcharged, undercharged and steady-state as described in Gagné et al. (2008). The classification was made by looking at the size distribution of the ambient and neutralized mode and comparing the concentrations of both modes for each polarity. The polarity and day was classified as overcharged if the concentrations of small particles was bigger in the ambient mode than in the neutralized mode; and as undercharged if they were smaller in the ambient mode than in the neutralized mode. It was classified as steady-state if both modes showed about the same concentrations. From a total of 246 NPF event days, 164 were found to be overcharged and 42 undercharged. In comparison, the DMPS-based classification by the method described by Dal Maso et al. (2005) gave the following numbers: for overcharged days, 64 class I events, 42 class II events, 45 were undefined according to the DMPS, and 2 were not seen as events; for undercharged days, 24 were class I events, 6 were in class II events, 10 undefined, and 1 was not classified as an event. On two days, one in each category, the DMPS was not working. In the IonDMPS classification, class I and II events are merged into the event day class.

Since the classification is given for both the positive and negative polarity, the classification for a given day was defined as follow: if both the negative and positive polarities were in agreement, the day was classified as overcharged or undercharged. If they were different, the event day was discarded. Thus, 40 event days were discarded because the class was not clear (11 days) or because the polarities were not classified in the same category ( 29 days). Of these 29 days, only one case of overcharged negative polarity and undercharged positive polarity was observed, indicating that both polarities had different chemical pathways in accordance with Eisele et al. (2006). All the other days showed a weak overcharging for one polarity and steady-state for the other one. These days are not uninteresting but they are hard to classify with respect to "little or no IIN" which is called undercharged in this study and "higher contribution of IIN" which is called overcharged in this study. They are cases in between, thus, in order to make the differences between the parameters easier to observe, those gray cases were discarded.

Aerosol populations that were classified as steady-state were considered undercharged in this study since the participation of ion-induced nucleation was at steady-state and thus had a low ion-induced fraction and thus belong to the "low IIN" class, undercharged. In the undercharged class, 25 days had both polarities at steady-state, and 7 days had one of the polarities at steady-state.

\subsubsection{Condensation sink, growth rate, and ion-induced fraction from the NAIS}

The condensation sink (CS) describes the removal rate of vapor molecules onto the pre-existing aerosol particles. It was calculated according to Kulmala et al. (2001) based on the aerosol size distribution in the $3-1000 \mathrm{~nm}$ size range measured with the DMPS.

The ion-induced fraction of the particle formation was calculated based on measurement data from the NAIS and the BSMA (Manninen et al., 2009a). The BSMA measures the naturally charged fraction of the aerosol, while the NAIS measures, in addition, the total particle concentration. The formation rate of $2 \mathrm{~nm}$ particles was calculated based on the method described in Kulmala et al. (2007a). The total formation rate $J_{2}$ is:

$J_{2}=\frac{d N_{2-3}}{d t}+\operatorname{CoagS}_{2} \cdot N_{2-3}+\frac{\mathrm{GR}}{1 \mathrm{~nm}} \cdot N_{2-3}$

where $N_{2-3}$ is the concentration of particles between 2 and $3 \mathrm{~nm}$, CoagS is the coagulation sink for $2 \mathrm{~nm}$ particles and GR is the growth rate of the particles in the initial steps of the particle formation. In calculating the formation rate of charged particles, $J_{2}^{ \pm}$, we also took into account the ion-ion recombination and charging of neutral particles in the $2-3 \mathrm{~nm}$ size range:

$$
\begin{aligned}
& J_{2}^{ \pm}=\frac{d N_{2-3}^{ \pm}}{d t}+\mathrm{CoagS}_{2} \cdot N_{2-3}^{ \pm}+\frac{\mathrm{GR}}{1 \mathrm{~nm}} N_{2-3}^{ \pm} \\
& +a \cdot N_{2-3}^{ \pm} \cdot N_{<3}^{\mp}-\beta \cdot N_{2-3} \cdot N_{<3}^{ \pm}
\end{aligned}
$$

It is important to note that the ion-induced fraction was averaged over the period $4.8-8.4 \mathrm{~h}$ after sunrise, because this is when the newly formed particles are being formed, on average, and thus the fraction is most stable. The ion-induced fraction is not interesting outside this period because there is no nucleation at that moment (and thus the formation rates are close to zero, the fraction varies a lot). Also, the days for which the data were available are limited to the clearest new particle formation days, which all took place during springtime. This dataset may not be representative of the whole 
yearly behavior and the results should be interpreted only as a test on a small specific sample.

\subsubsection{Sulfuric acid}

Atmospheric sulfuric acid concentrations were predicted by the new model SOSA (model to simulate concentrations of organic vapors and sulfuric acid in the lower troposphere). SOSA was developed in the first half of 2009 at the University of Helsinki based on sulfuric acid closure (Boy et al., 2005). The meteorology is based on a 1-D version of the model SCADIS (Sogachev et al., 2002; Sogachev and Panferov, 2006) and the Model for Emissions of Gases and Aerosols in Nature (MEGAN, Guenther et al., 2006) is used to simulate the emission of organic vapors from the biosphere. The gas phase chemistry is solved with the Kinetic PreProcessor (Sandu and Sanders, 2006, and http://people.cs.vt.edu/ asandu/Software/Kpp/) in combination with the Master Chemical Mechanism (MCM, http: $/ / \mathrm{mcm}$.leeds.ac.uk/MCM/) from the University of Leeds. It is a parallelized model operating on the high-performance supercluster Murska at the CSC - IT Center for Science in Finland, which gives the possibility to run detailed processes in chemistry, aerosol dynamic and meteorology within reasonable time. The model uses meteorological and various other input data (inorganic gas concentrations, aerosol properties and radiation data) measured in Hyytiälä to minimize the uncertainty in the simulated parameters. The vertical resolution of the model is up to $3 \mathrm{~km}$ in 75 levels increasing exponentially from the ground to the model top which provides very detailed information about the fluxes inside and above the canopy. A manuscript presenting an overview of the model is under preparation.

\subsubsection{Hydration state calculations}

To assess and illustrate possible differences in the role of water between the overcharged and undercharged events, the hydration state of sulfuric acid molecules $\left(\mathrm{H}_{2} \mathrm{SO}_{4}\right)$, i.e. the number of water molecules attached to sulfuric acid, were modeled using the measured water vapor concentration and temperature together with the hydration free energies. They were computed using quantum chemistry simulations by Kurtén et al. (2007), and specifically the parametrisations given therein. First, the Gibbs free energy of hydrate formation (i.e. the free energy change for the addition of $0-4$ water molecules to $\mathrm{H}_{2} \mathrm{SO}_{4}$ ) was computed from the given parametrisations at each temperature. Next, the relative concentration (percentage) of $\mathrm{H}_{2} \mathrm{SO}_{4}$ molecules bound to 0,1 , 2, 3 or 4 water molecules was computed from the law of mass balance (also known as the law of chemical equilibrium) using this free energy change and the measured absolute water concentration. Finally, the average number of water molecules bound to $\mathrm{H}_{2} \mathrm{SO}_{4}$ was computed as a weighted average of the relative concentrations.

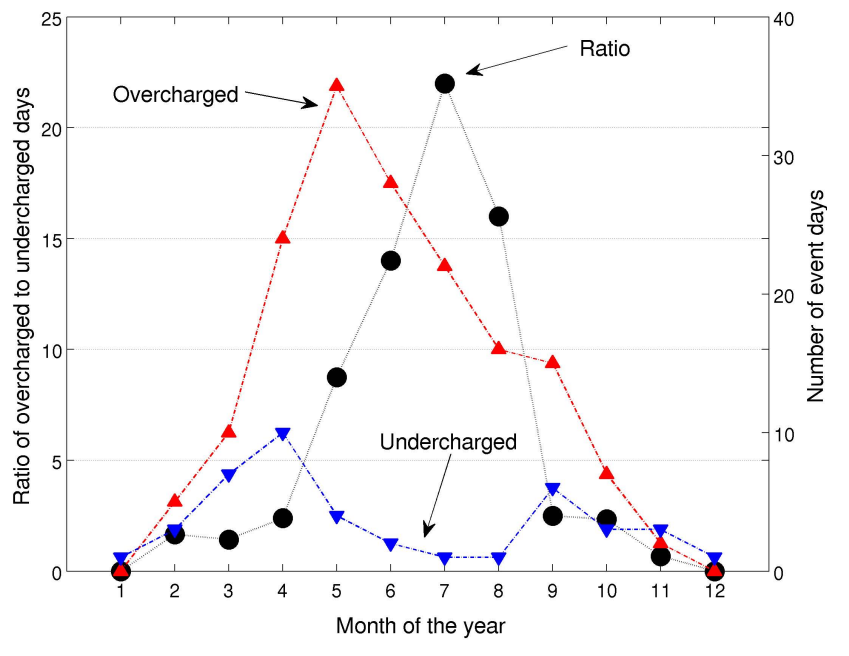

Fig. 1. Ratio of overcharged events to undercharged events for each month over the 2005-2007 period (black circles, left vertical axis). The number of event days is also presented for overcharged days (in red) and undercharged days (in blue), and report to the right vertical axis.

\section{Results}

\subsection{General presentation of the data}

\subsubsection{Annual variation of over- and undercharged days}

The results presented in this section discuss the charging state of the particles i.e. which fraction of particles are charged compared to the charged fraction in the steady-state artificially created by an aerosol charger. The charging state varies in time and depends on the particle size. However, new particle formation events show characteristics of either more or less charges than the steady state at sizes close to where the nucleation occurs (around $2 \mathrm{~nm}$ ). Because of this, it is practical to present the results based on this classification (Gagné et al., 2008). In addition to these two relatively well-defined situations, more complex situations with altering charging state characteristics during the course of an event may also take place (Laakso et al., 2007b), but this is not covered in this work.

After the measurement days were categorized into overand undercharged days, the data showed a clear seasonal pattern in their relative distribution (Fig. 1). While the total number of new particle formation event days was the largest in spring (April and May), overcharged events dominated during the summer months and undercharged ones became more important in winter. In fact, overcharged NPF event days were more frequent during most the year and undercharged days took over between November and January, around the winter solstice. In spring and autumn, overcharged events were more common but undercharged events also took place regularly. In winter, however, overcharged 


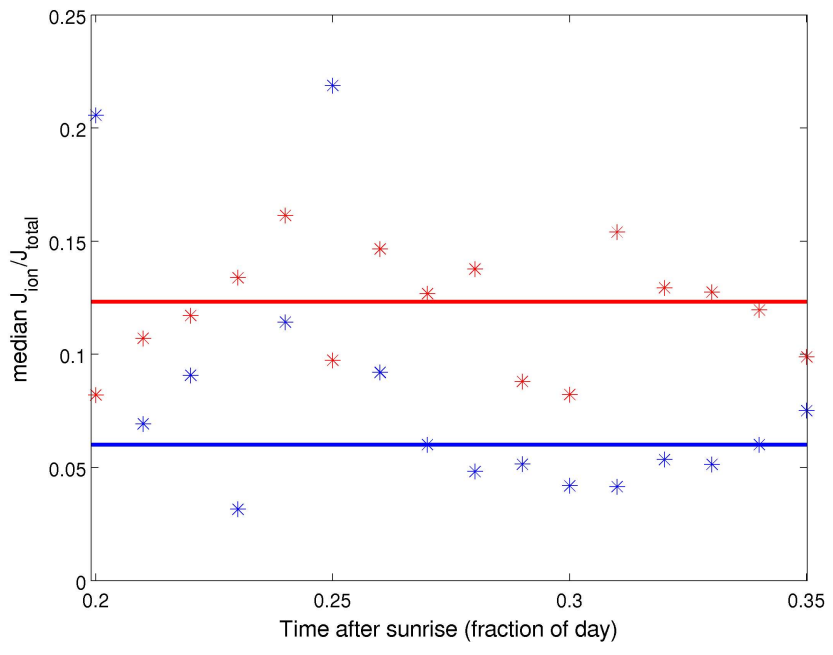

Fig. 2a. Fraction of ion-induced nucleation as a function of the time after sunrise. The median ion-induced nucleation fraction is calculated using the formation rate of $2 \mathrm{~nm}$ charged particles divided by the total formation rate of $2 \mathrm{~nm}$ particles from NAIS measurements. The median fraction for 28 overcharged days is shown in red, for 8 undercharged in blue. The horizontal lines represent the median value between 0.2 and 0.35 days after the sunrise (when the event is taking place, on average).

events became very rare, and so did undercharged events in summer. It should be noted that the number of events was small in winter. This annual distribution of over- and undercharged events has to be taken into account when performing the analysis of other parameters that also vary on a seasonal basis. For example, temperature varies between summer and winter and the large number of overcharged events during the summer will affect the average values. In these kinds of cases, the summer months were removed altogether so that the high number of summer overcharged events would not dominate the statistics.

\subsubsection{Comparison of the ion-induced contribution derived from Ion-DMPS and NAIS}

In order to assess how accurately the Ion-DMPS classification reflects the fraction of ion-induced nucleation taking part in a new particle event, it was compared to the fraction derived from the NAIS measurements. The classification based on the Ion-DMPS aerosol size distributions was compared to the ion-induced nucleation fraction calculated from the formation rates of charged and neutral particles, with a NAIS, at $2 \mathrm{~nm}$ as described in Kulmala et al. (2007) and in Manninen et al. (2009a). The data was available for 44 days over the period covered in this paper, of which 28 were overcharged and 11 were undercharged. Five days were in neither of the categories and it was impossible to obtain reasonable numbers for 3 undercharged days because of too small charged particle concentrations. All of the days occurred during the

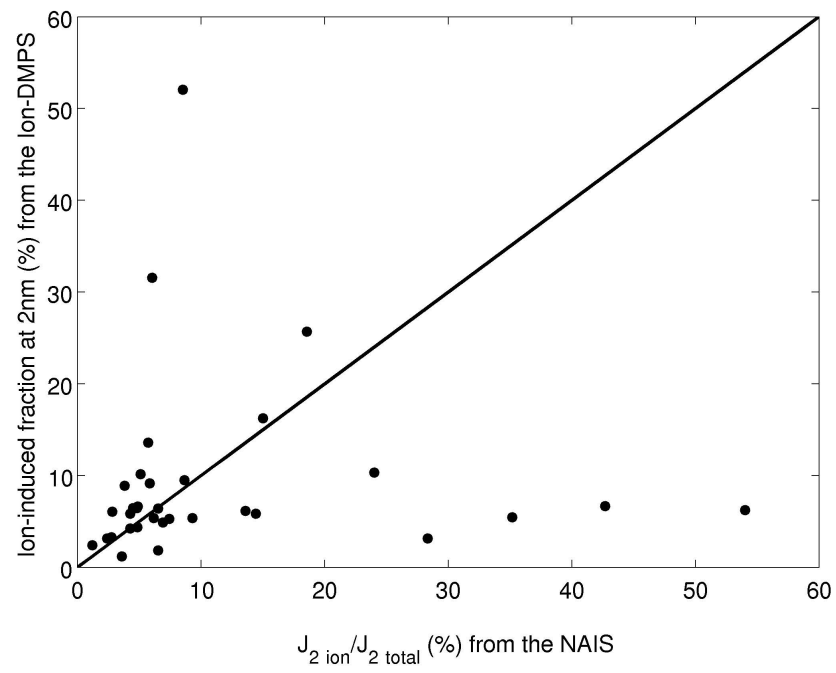

Fig. 2b. The Ion-induced fraction calculated for events of 2006 and 2007 are compared for the NAIS measurements and method and the Ion-DMPS measurements and method.

spring, but this does not invalidate the comparison because those events covered a wide range of ion-induced nucleation fraction. The median value of the ion-induced fraction during the overcharged events was twice as high than for undercharged events (Fig. 2a). This indicates that the classification based on the Ion-DMPS data is in agreement with the one derived from the NAIS measurements. One should note that these two methods are completely independent from each other. Figure 2a shows that the fraction of ion-induced nucleation becomes less important in the middle of the event (after $7 \mathrm{~h}$ after sunrise). It therefore seems that ion-induced nucleation is more important at the beginning of the event in agreement with the thermodynamic principle described in Kulmala et al., 2007b and observed by Winkler et al., 2008 according to which charged particles activate with a smaller saturation ratio than neutral particles.

Figure $2 \mathrm{~b}$ shows the comparison between the ion-induced nucleation fractions calculated from the NAIS (Manninen et al., 2009) and extrapolated from the Ion-DMPS data (Kerminen et al., 2007). In general, both methods showed a similar tendency. There were, however, a few points with especially large ion-induced fractions for only one of the methods. Both methods have their strengths and weaknesses. While the extrapolation method is sensitive to uncertainties in Ion-DMPS measurements and requires well-behaved data points, it usually gives a good idea on whether the event is over- or undercharged. The method based on NAIS measurements is most inaccurate when the value of $J_{\text {ion }}$ approaches that of $J_{\text {tot }}$, or when $J_{\text {tot }}$ is small. Due to different reasons causing uncertainties in determining the ion-induced fraction with these two methods, it is not surprising that we have a few extreme points in Fig. 2b. Once these outliers are removed, the NAIS with its formation rate ratio compares fairly well 


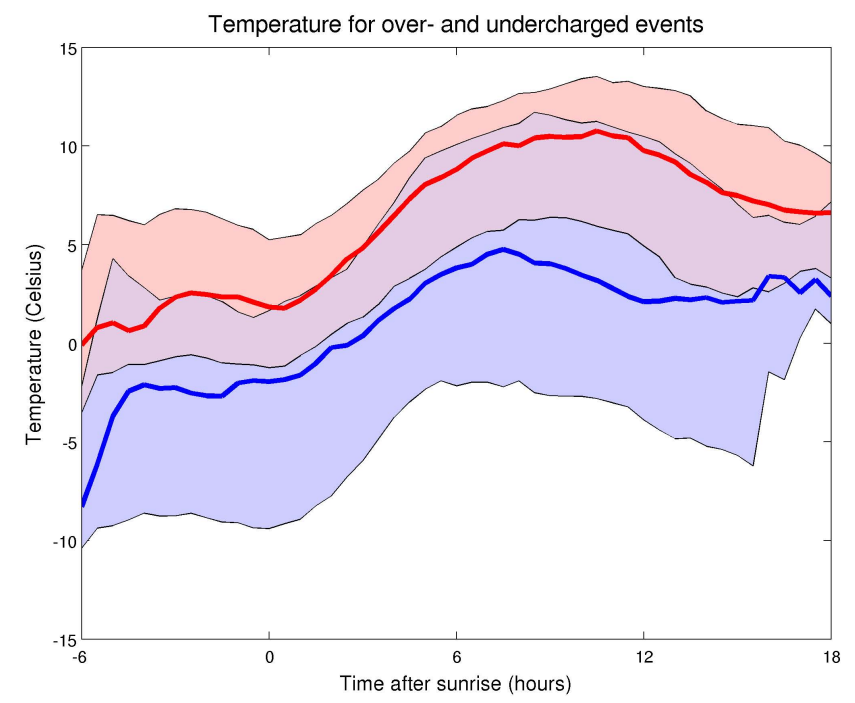

Fig. 3a. The median temperature for all overcharged days (in red) and undercharged days (in blue) excluding summer months. The filled areas represent the 25 th to 75 th percentiles. The temperature difference excluding summer months is still around 5 degrees Celsius, with warmer temperatures for overcharged days. When all the data points are included, the temperature difference increases to about 8.5 degrees Celsius.

with the charging state extrapolation method applied to the Ion-DMPS measurements.

\subsection{Relation between over- and undercharged events and other measured quantities}

\subsubsection{Meteorological parameters and solar radiation}

The median temperature of overcharged days was higher than that of undercharged days. The difference between the median temperatures was about 8.5 degrees Celsius when the whole year was taken into account. However, as mentioned earlier, this could be due to the seasonal distribution of overcharged and undercharged days. When the summer months (June-July-August) were removed from the analysis, the temperature still remained significantly higher during overcharged days compared to undercharged days. The difference between the median temperatures was still around 5 degrees Celsius (Fig. 3a). However, the temperature does not seem to be a clear indicator of the fraction of ion-induced contribution to new particle formation with respect to the total particle formation. Indeed, the correlation between temperature and the ion-induced fraction calculated from NAIS measurements was very weak. In order to show that the temperature difference is not only caused by a seasonal tendency, the temperature on each day was compared with a seasonal average. Figure $3 b$ shows the temperature difference between the mean temperature on the event day and the average temperature on that same day since 1996, with a 10 days

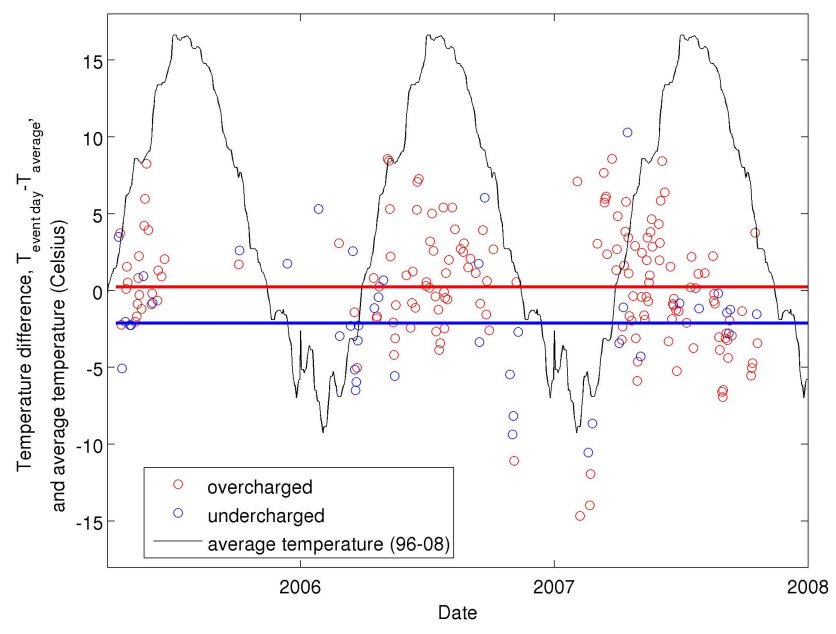

Fig. 3b. The temperature difference between each event day and a 1996-2008 average for the same day is presented for overcharged (in red) and undercharged (in blue) events. The medians for overand undercharged days were $0.23{ }^{\circ} \mathrm{C}$ and $-2.13{ }^{\circ} \mathrm{C}$ (horizontal red and blue lines, resp.) and the means were $0.32^{\circ} \mathrm{C}$ and $-1.87^{\circ} \mathrm{C}$, respectively. The black line shows the 12 year average temperature smoothened over 10 days.

smoothing. Overcharged days took place on a median temperature of 0.23 above the average, and undercharged days with a median temperature of 2.13 below the average. Both samples were different at a value of $p=0.002$, where $p$ is the probability of having such a difference if the numbers were normally distributed, obtained with a t-test. In the remainder of the text we always use the word p-value for designating the probability obtained from a t-test.

The connection between the intensity of solar radiation and the ion-induced fraction was also examined because it is often related to the ambient temperature. The net and global solar radiation levels were indeed higher for overcharged days than they were for undercharged days, even when the summer months were discarded. Also, the solar radiation was generally higher on event days compared to non-event days. Using the same method as in Fig. 3b, we got a median difference of 65.7 and $35.5 \mathrm{Wm}^{-2}$ for overcharged and undercharged days respectively compared to the mean of the previous years at the same time of the year. The p-value for these two samples was 0.001 . The global radiation had a better correlation with the fraction of ion-induced nucleation than temperature did, although not significant in both cases (around 0.09 and 0.01 for global radiation and temperature, respectively). The correlation coefficients for both temperature and global radiation were calculated based only on approximately 40 springtime new particle formation events, so the sample was limited and not necessarily representative of the whole analyzed period. 


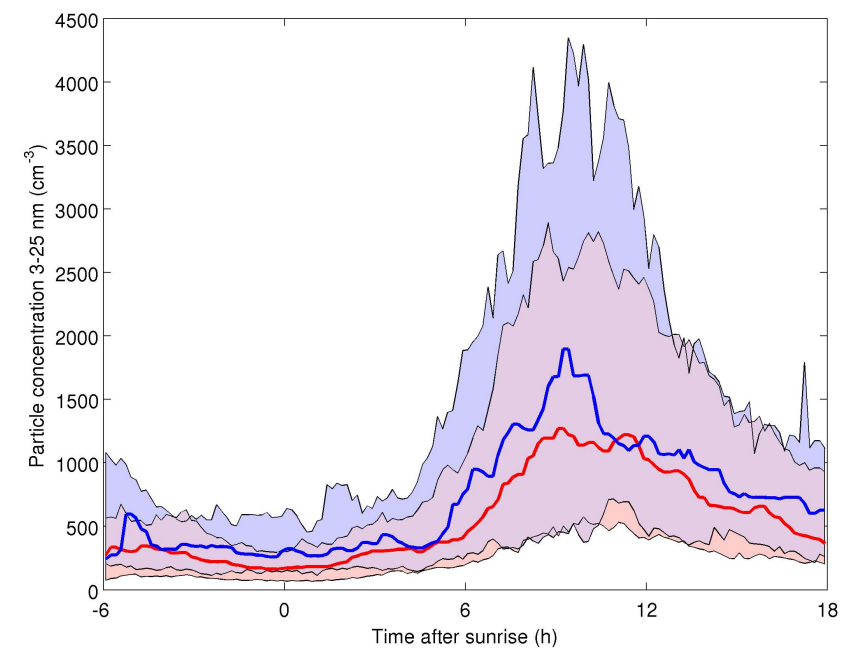

Fig. 4. Nucleation mode particles (3 to $25 \mathrm{~nm}$ ) measured with a DMPS. Higher concentrations of nucleation mode particles are nucleated on undercharged days (median, blue line) than on overcharged days (median, red line). The 25 th to 75 th percentiles range is given by blue and pink filled areas (purple is where both ranges are superposed).

The relative humidity was about $10 \%$ higher for undercharged days compared to overcharged days when including summer months. However, the absolute humidity (water content) was higher for overcharged days than for undercharged days (likely because of the temperature difference). Using the method shown in Fig. 3b, we got a median difference in relative humidity of $-17.5 \%$ and $-12.9 \%$ for overcharged and undercharged days respectively compared to the mean of the previous years at the same date. The p-value was only 0.104 in this case, which means that the probability of haven got this difference from normally distributed numbers was around $10 \%$. The negative values show that events take place at lower relative humidity than non-events, in agreement with the literature (e.g. Boy and Kulmala, 2002 and Vehkamäki et al., 2004). Overcharged days seem to take place, on average, during dryer (lower relative humidity) and warmer days, when the amount of solar radiation is high.

\subsubsection{Particle concentrations}

As observed by Vana et al. (2006), a higher contribution from ion-induced nucleation seems to be connected with smaller concentrations and undercharged nucleation with higher concentrations of nucleated particles. In Fig. 4, one can see that the median concentration of nucleation mode particles was higher on undercharged days (blue line) than on overcharged days (red line). On overcharged days the median peak concentration reached 1200 particles $\mathrm{cm}^{-3}$, whereas on undercharged days it reached around 1900 particles $\mathrm{cm}^{-3}$. The over- and undercharged samples were different with a p-value of 0.033 . The concentrations in Aitken (25-100 nm)
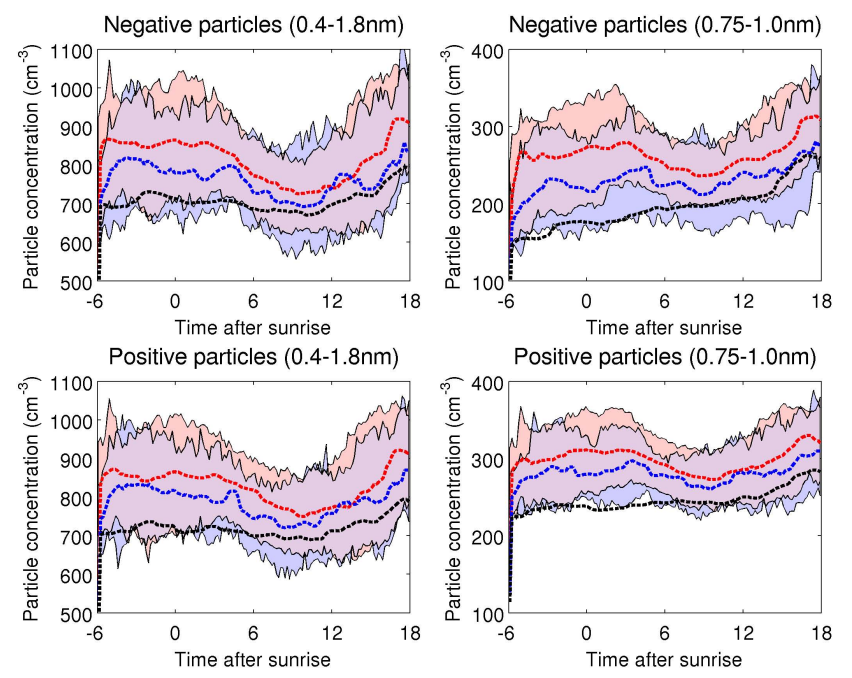

Fig. 5. Electrically charged particle concentration below the activation size as a function of the time spent after sunrise for (a) 0.4 to $1.8 \mathrm{~nm}$ particles on the left and (b) 0.75 to $1.0 \mathrm{~nm}$ particles on the right (Tammet diameter). The median concentrations for overcharged days are in red and for undercharged days, in blue. The median on non-event days are also added for comparison in black. The colored areas represent the 25th to 75th percentiles (for overand undercharged days only). Negatively charged particles are in the upper part of the plot and the positively charged ones in the lower part of the plot.

and accumulation (100-500 nm) modes did not show any noticeable difference between over- and undercharged days.

\subsubsection{Charged nanoparticles}

In order to investigate whether the ions participating in ion-induced nucleation originate from the pool of charged nanoparticles smaller than $2 \mathrm{~nm}$, the median concentration of negatively and positively charged particles between 0.4 and $1.8 \mathrm{~nm}$ and between 0.75 and $1.0 \mathrm{~nm}$ from BSMA measurement (Tammet diameter) as a function of the time after the sunrise are presented in Fig. 5a and b respectively. In both diameter ranges and both polarities, the concentration of charged nanoparticles was higher for overcharged days than for undercharged days. No noticeable difference between over- and undercharged days for the ion pair production rate due to radon daughter decay was found. It should also be noted that in the 0.75 to $1.0 \mathrm{~nm}$ range, there were generally much higher concentrations in summer than in winter. However, this tendency was not observed in the $0.4-1.8 \mathrm{~nm}$ range, hence concentration difference was not only due to the seasonal distribution of over- and undercharged event days and removing the summer months did not change the tendency.

A drop in the concentration of charged nanoparticles smaller than $1.8 \mathrm{~nm}$ was observed when the nucleation events started. The condensational sink (CS) was not responsible for this as its value also dropped just before the new 
particle formation event; an increase in CS could cause the removal of small charged particles from the pool. No noticeable difference between overcharged and undercharged days was seen for the condensational sink (not shown). The radon daughters cannot explain this either, because the drop in their concentration, due to boundary layer height change during the day, is more important for undercharged days. We would then expect the drop to be this way also for nanoparticle concentrations. When the BSMA channels were analyzed one by one, the drop during the event time was noticed most clearly in the 0.75 to $1.0 \mathrm{~nm}$ range (Fig. $5 \mathrm{~b}$ ). In the 0.75 to $1.0 \mathrm{~nm}$ range, the median concentration of charged nanoparticles was lower for non-event days. Note that the drop in the ions smaller than $1.8 \mathrm{~nm}$ (Tammet diameter, corresponding to around $2.2 \mathrm{~nm}$ in Millikan diameter) took place at the same time as the rise in nucleation mode particle concentration, about $4 \mathrm{~h}$ after the sunrise (Fig. 4). The dip was more pronounced for overcharged days in absolute number concentration for both polarities and both size ranges. The percentage of charged nanoparticles disappearing from their pool was also larger for overcharged days than for undercharged days for all the size ranges and polarities of Fig. 5 except for positively charged nanoparticles between $0.75-1.0 \mathrm{~nm}$ (see Table 1). The difference in the fraction of "activated" ions was more important for negatively charged nanoparticles. The sign preference of ion-induced nucleation towards the negatively charged kernels have been observed in field measurements, laboratory experiments, and quantum chemical simulations (e.g. Vana et al., 2006; Winkler et al., 2008; Kurtén et al., 2009).

\subsubsection{External radiation}

The external radiation consists of ionizing gamma rays traveling in the atmosphere. Due to its ionizing properties, external radiation can be a good candidate for triggering ioninduced nucleation. The median ion pair production rate due to gamma radiation was around 9.1 ion pairs s $\mathrm{s}^{-1} \mathrm{~cm}^{-3}(25$ th and 75 th percentile around 6.0 and 9.6 ion pairs $\mathrm{s}^{-1} \mathrm{~cm}^{-3}$ respectively) for undercharged days, and for overcharged days it was around 9.7 ion pairs $\mathrm{s}^{-1} \mathrm{~cm}^{-3}$ (25th and 75 th percentile around 9.3 and 10.3 ion pairs $\mathrm{s}^{-1} \mathrm{~cm}^{-3}$ respectively). This is not a big difference when considering that the uncertainty on this value was estimated to be around $10 \%$. However, even though the ion pair production rate does not seem to influence the concentration of charged nanoparticles, it seems to have a relation with the formation rates of $2 \mathrm{~nm}$ charged particles calculated from NAIS measurements. Although the NAIS was also measuring during other seasons, the formation rates were available only for days during spring. This is because formation rates are most reliable only for the strongest NPF events, which happened to all take place in spring, in this study. Since the NAIS data only came from spring days, this may not be true for the whole year. The formation rates of $2 \mathrm{~nm}$ charged particles
Table 1. The fraction of small particles removed from the pool of charged nanoparticles during new particle formation events. The calculations are based on the medians of all days as they appear in Fig. 5. The dip is always bigger for overcharged days: in concentrations for all 4 categories (size range and polarity), and in percentage for 3 out of 4 . The difference is more important for negatively charged particles.

\begin{tabular}{|c|c|c|}
\hline \multicolumn{3}{|c|}{$\begin{array}{l}\text { Fraction of charged nanoparticles removed from their pool } \\
\text { during new particle formation events }\end{array}$} \\
\hline & $\begin{array}{l}\text { Overcharged } \\
\text { (median) }\end{array}$ & $\begin{array}{l}\text { Undercharged } \\
\text { (median) }\end{array}$ \\
\hline \multicolumn{3}{|c|}{$0.4-1.8 \mathrm{~nm}$ ( 5 channels $)$} \\
\hline Negatively charged & $16 \%$ & $12 \%$ \\
\hline Positively charged & $13 \%$ & $10 \%$ \\
\hline \multicolumn{3}{|c|}{$0.75-1.0 \mathrm{~nm}$ ( 1 channel $)$} \\
\hline Negatively charged & $17 \%$ & $9 \%$ \\
\hline Positively charged & $12 \%$ & $13 \%$ \\
\hline
\end{tabular}

increased with the increasing ion pair production rate due to external radiation. This relation was stronger for positively charged particles than for negatively charged particles. No difference between overcharged and undercharged days was noticed as the formation rates increased in the same way for both classes. During the days when the soil was covered with snow (and $<8.5$ ion pairs s $\mathrm{s}^{-1} \mathrm{~cm}^{-3}$ ), the formation rates of charged particles did not lie on the same line, the points were scattered. This could be due to smaller particle formation rates and hence more uncertainty on the formation rate on these days.

An interesting relation between ion pair production rate by external radiation and the water content in the soil and snow cover was observed, as described by Hatakka et al. (1998). In winter, the external radiation is blocked by the snow cover on top of the soil. During that period, less water penetrates into the soil and the soil humidity decreases along with the ion production rate. In spring, when the snow melts, the water penetrates into the soil and the soil humidity along with the ion production rate due to external radiation increases. During the summer, the ion production rate is anti-correlated to the water content in the soil, as water in the upper parts of the soil is absorbing part of radiation energies. The effect of water is more important when the water is in the part of the soil closer to the surface, so that it is above the radiation source. This may explain why many overcharged events were observed in the summer of 2006 when the boreal forest in Hyytiälä was undergoing a drought. 

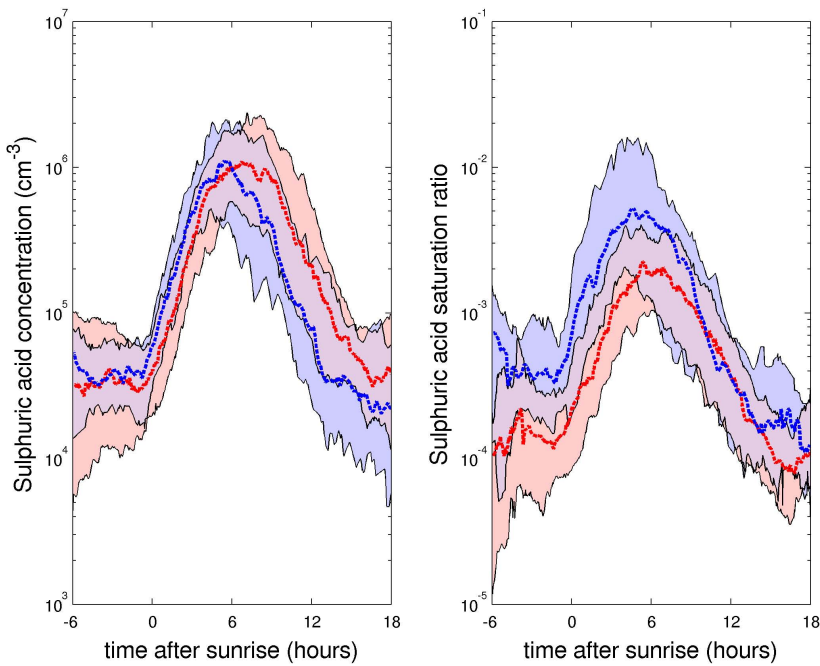

Fig. 6. (a) Median sulfuric acid concentration (modeled, SOSA) on overcharged days (red) and undercharged days (blue). (b) Median sulfuric acid saturation ratio (modeled, SOSA) on overcharged days (red) and undercharged days (blue). The 25th to 75th percentiles are represented by the filled areas. In this picture, the summer months have been removed.

\subsubsection{Growth rates}

The growth rates of charged particles were similar for both overcharged and undercharged days. However, for neutral particles (calculated based on DMPS data; Hirsikko et al., 2005 ) in the 3 to $7 \mathrm{~nm}$ range, the average growth rate was higher for undercharged days. The mean growth rate during the April 2005 to June 2007 period (due to unavailability of the data for the second half of 2007) was $3.7 \mathrm{~nm} \mathrm{~h}^{-1}$ for overcharged days and $5.2 \mathrm{~nm} \mathrm{~h}^{-1}$ for undercharged days. The corresponding median values were 2.6 and $5.2 \mathrm{~nm} \mathrm{~h}^{-1}$.

\subsubsection{Sulfuric acid and hydration}

Since sulfuric acid is a strong candidate for participating in atmospheric nucleation (e.g. Weber at el., 1996; Birmili et al., 2003; Stanier et al., 2004; Riipinen et al., 2007; Kulmala and Kerminen, 2008), its modeled concentration as well as its saturation ratio were analyzed. Furthermore, since the sulfuric acid concentration may vary seasonally, and more importantly its saturation ratio is influenced by the ambient temperature, median values were calculated excluding the summer months (Fig. 6). The median sulfuric acid concentration (Fig. 6a) was higher for undercharged days than for overcharged ones, but only at the beginning of the events. The difference was, however much more noticeable for the saturation ratio (Fig. 6b), with a t-test p-value of 0.019 on the logarithm of the saturation ratio. Of course, the temperature difference has an amplifying effect on the saturation ratio difference. The difference was bigger when including

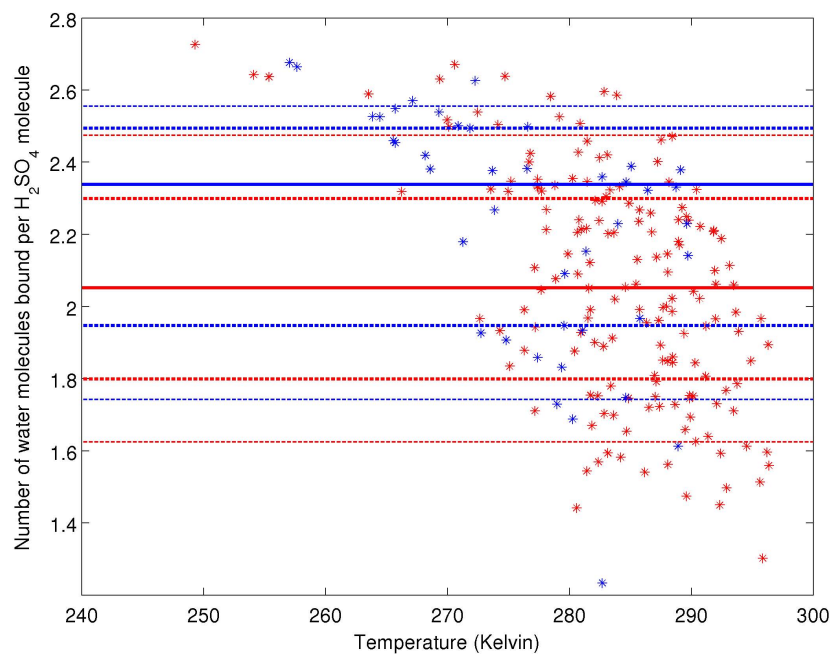

Fig. 7. The number of water molecules attached to sulfuric acid as a function of the temperature for overcharged (red dots) and undercharged (blue dots) days. The full lines represent the median of all over- (red) and undercharged (blue) days, the short and thick dashed lines are the 25th and 75th percentiles, and the long thin dashed lines are the 10th and 90th percentiles with the same color coding.

the summer months. In that case, the t-test yielded a p-value of $0.02 \%$.

Simple quantum chemistry calculations were made to illustrate possible differences in the participation of water in nucleation (assumed here to involve mainly sulfuric acid and water) for over- and undercharged days. The average number of water molecules bound to $\mathrm{H}_{2} \mathrm{SO}_{4}$ molecules were calculated using the average temperatures and relative humidity for each classified new particle formation event day, as described in Sect. 2.2.4 (Fig. 7). One can see that, on average, undercharged days (blue dots) had a greater number of water molecules bound to $\mathrm{H}_{2} \mathrm{SO}_{4}$ molecules than overcharged days (red dots). This can also be seen when looking at the percentile statistics. Qualitatively, this is reasonable. For example, while the $\mathrm{HSO}_{4}^{-}$ion (probably one of the main anions acting as seeds in ion-induced nucleation) binds water only slightly more strongly than neutral $\mathrm{H}_{2} \mathrm{SO}_{4}$ does, its binding to additional neutral $\mathrm{H}_{2} \mathrm{SO}_{4}$ molecules is immensely stronger. (The differences between $\mathrm{HSO}_{4}^{-}$and neutral $\mathrm{H}_{2} \mathrm{SO}_{4}$ in binding to water and additional $\mathrm{H}_{2} \mathrm{SO}_{4}$ molecules are $3-4 \mathrm{kcal} / \mathrm{mol}$ and around $30 \mathrm{kcal} / \mathrm{mol}$, respectively, based on data from Kurtén et al. 2007 and 2008.) Thus, the number of water molecules in a charged $\mathrm{HSO}_{4}^{-}-\mathrm{H}_{2} \mathrm{SO}_{4}-\mathrm{H}_{2} \mathrm{O}$ critical cluster is likely to be significantly smaller than in a neutral $\mathrm{H}_{2} \mathrm{SO}_{4}-\mathrm{H}_{2} \mathrm{O}$ critical cluster, and the dependence of nucleation rates on water concentrations is likely significantly lower for ion-induced than for neutral nucleation. As the preference for $\mathrm{H}_{2} \mathrm{SO}_{4}$ toward 
anions is mainly due to its high acidity (see e.g. Kurtén et al., 2009, for a discussion), a similar pattern very likely applies also for other core anions than $\mathrm{HSO}_{4}^{-}$. Even though it is thought that other compounds also form the critical cluster, sulfuric acid and water almost certainly are part of it, hence the relevance of the proportion of water in ion-induced and neutral clusters.

\section{Discussion}

Substantial differences between overcharged (involving ioninduced nucleation) and undercharged (involving no or very little ion-induced nucleation) new particle formation events were found. The most striking and unexpected of these was the difference in the temperature (Fig. 3). Solar radiation, while it was also higher on overcharged days, does not seem a likely candidate for influencing the mechanism. It is known that higher solar radiation levels seem to be required to trigger new particle events regardless of the mechanism involved (Boy and Kulmala, 2002). It is important to keep in mind that global solar radiation does not ionize the lower atmosphere. Nevertheless, solar radiation may have an influence on chemical reactions that contribute to one mechanism more than another since it is thought to induce vertical mixing and photochemistry (Nilsson et al., 2001).

In neutral nucleation there usually is an activation energy barrier that depends on temperature in many ways (directly and through other variables). In ion-induced nucleation, this energy barrier is reduced, sometimes even removed, because of the induced dipole caused by the presence of the charge in the seed particle and the corresponding binding between the core ion and the molecules of the nucleating vapor. Correspondingly, the critical cluster (the smallest cluster for which growth is more likely than evaporation) is smaller for ioninduced than for neutral nucleation, at least if the nucleating substances are the same. Since temperature increases the collision rate but increases evaporation to a much greater degree, a rise in temperature will, in general, decrease nucleation rates (see e.g. Lovejoy et al., 2004). As the number of temperature-sensitive steps (i.e. the number of molecules in the critical cluster) is smaller in ion-induced nucleation than in neutral nucleation, ion-induced nucleation is likely to be less temperature sensitive than neutral nucleation, and the ion-induced nucleation rate will decrease less as the temperature increases. The magnitude of this effect is unfortunately hard to assess quantitatively as the molecular-level mechanisms for both neutral and ion-induced nucleation are, as yet, unknown. Other parameters, such as seasonally dependent volatile organic compound emission, might also influence the nucleation mechanism.

Overcharged events also required smaller sulfuric acid saturation ratios than undercharged ones (Fig. 6). It has been shown that the formation rate of particles is proportional to the concentration of sulfuric acid to the power 1-2 (see e.g. Kulmala et al., 2006; Riipinen et al., 2007; Kuang et al., 2008; Nieminen et al., 2009). The observation that overcharged days had lower saturation ratio of sulfuric acid than undercharged days, on average, may imply that particles growing on charged seeds may need fewer sulfuric acid molecules to bind before it overcomes the energy barrier and activates than those growing neutrally. It has been observed experimentally that charged particles (negative first, then positive) activate with lower vapor saturation ratios than neutral particles (Winkler et al., 2008). Undercharged days were characterized by a higher average number of water molecules bound to $\mathrm{H}_{2} \mathrm{SO}_{4}$, possibly indicating a larger number of water molecules needed to stabilize the critical clusters in neutral nucleation pathways. This supports the idea that ion-induced nucleation is achieved more easily when it comes to condensible vapors availability.

The higher nuclei growth rates on undercharged days support the idea that there are generally more nucleating vapors available on those days and that they contribute both to nucleation and growth. Although sulfuric acid (and water) availability cannot explain all of the growth it probably contributes to some fraction (Boy et al., 2003, 2005). Also, based on the difference between over- and undercharged days on vapor availability, it could be interesting to verify that the relation of ion-induced nucleation and neutral nucleation formation rates with sulfuric acid concentrations or saturation ratios have different dependences (slopes).

The fact that growth rates were bigger on undercharged days has another implication when considering the work by Kerminen et al. (2007). They developed a method to extrapolate the charging state (that is how charged the particle population is compared to the equivalent steady-state population) to smaller sizes from Ion-DMPS data. This extrapolation method is valid only if the information about the charging state is preserved until the detection size $(3 \mathrm{~nm})$. This is the case when the nuclei grow fast enough. If the nuclei growth rate is low, information about the original charging state will be lost before the particles reach detectable sizes. This means that if undercharged days generally had higher growth rates than overcharged days, it is unlikely that undercharged days had in reality been overcharged days for which the "memory" had been lost.

External radiation consists of high energy photons that can ionize the lower troposphere and could affect the contribution of ion-induced nucleation to the total nucleation rate. The ion pair production rate due to external radiation correlated with the formation rate of $>2 \mathrm{~nm}$ ions on days when the soil was not covered with snow. The contribution from galactic cosmic rays is about constant throughout the year while the contribution coming from the soil (about $2 / 3$ of the total radiation) varies depending on e.g. snow cover and water content in the soil (Hatakka et al., 1998). The dependence of the formation rate of charged particles on external radiation seems to be the same for both overcharged and undercharged days. The total formation rate, consisting of both charged 
and electrically neutral particles did not, however, increase as the external radiation level increased. This suggests that the number of particles nucleated through ion-induced nucleation depends on the level of external radiation.

Another interesting observation was the behavior of charged nanoparticles from BSMA measurements (Fig. 5). The concentration of charged nanoparticles $(<2 \mathrm{~nm})$ was higher, on average, on overcharged days than on undercharged days. This could be due, for example, to the higher solar radiation level and its influence on atmospheric chemistry and/or the higher level of external radiation. As one can see in Fig. 5, a larger dip in the concentration of charged nanoparticles was observed on days having a higher fraction of ion-induced nucleation (overcharged) than on days with less ion-induced nucleation (undercharged), suggesting that a bigger number of charged nanoparticles were activated on overcharged event days. Since the condensational sink was about the same during over- and undercharged days, scavenging by larger pre-existing particles does not explain the difference in charged nanoparticles concentrations before the start of the event or the drop in their concentration. However, it is also important to note that the drop in percentage (Table 1) is bigger for overcharged days, especially for negative particles. The activation of a bigger fraction and concentration of charged nanoparticles on overcharged days implies that the ion-induced contribution to concentration varies and is more important on overcharged days.

Undercharged events produced more nucleated particles than overcharged events (Fig. 4). While the production of particles through ion-induced nucleation may be modulated by external radiation, the production by neutral mechanisms seems to be modulated by temperature. This means that when the temperature gets higher, the number concentration of freshly nucleated particles coming from neutral nucleation decreases while the number concentration from ion-induced nucleation stays about the same. Consequently, the fraction of ion-induced nucleation (IIN/total) would be larger on days with higher temperatures.

Also, the ion-induced fraction calculated based on NAIS measurement during the event gives an interesting insight (Fig. 2a). The ion-induced fraction dropped approximately 7-8 $\mathrm{h}$ after sunrise when the concentration of newly formed particles was still relatively low compared to its peak (Fig. 4). Later on, when the concentration reached its peak value, neutral nucleation seemed to play a bigger role than it was at the beginning of the event. This phenomenon has also been observed by Laakso et al. (2007b), and supported by thermodynamical principles of atmospheric nucleation (Kulmala et al., 2007b) according to which several mechanisms can take place at the same time. The concentration of charged nanoparticles (Fig. 5) did not recover immediately when the ion-induced fraction decreased, suggesting that the ioninduced new particle production is probably still the same, but the contribution of neutral nucleation is increasing, making the ion-induced fraction smaller. Neutral mechanisms taking over during an event shows that neutral nucleation can start after ion-induced nucleation has begun; ion-induced nucleation does not seem to monopolize the condensing vapors.

\section{Conclusions}

In this work, we have established that the Ion-DMPS classification of event days into overcharged and undercharged days is in general agreement with the ion-induced fraction calculated based on NAIS measurements. We showed that, in Hyytiälä, days with a bigger fraction of ion-induced nucleation tended to occur on warmer, dryer (lower relative humidity), and sunnier days and more often during the summer time. We also propose an explanation on how these meteorological parameters affect the nucleating mechanisms, especially in the case of temperature. The modeled sulfuric acid saturation ratio was smaller on overcharged days, supporting the idea that charged seeds activate at lower vapor saturation ratio. The relative humidity was also lower on overcharged days and, according to quantum chemistry calculations, a lower number of water molecules were bound to sulfuric acid. Due to the clear seasonal trend, there are probably other factors that promote ion-induced nucleation or limit neutral nucleation, for example an increase in abundance of volatile organic compounds in summer. The concentration of charged nanoparticles, as measured with a BSMA, was bigger on overcharged days. The removal of these nanoparticles from their pool during the new particle formation was more pronounced on overcharged days. The higher concentration of nanoparticles may be due to atmospheric chemistry (amount of solar radiation) or external radiation levels, while the removal from their pool may show that charged seeds activate. The growth rates of undercharged days were larger than those of overcharged day for total (neutral + charged) particles, the difference in sulfuric acid may be playing a part in this phenomenon.

Finally, it seems that both ion-induced and neutral nucleation are taking place in a same nucleation event, yet in different proportions during an event and also between different days. It seems that neutral nucleation can take place after ion-induced nucleation has started, meaning that ion-induced nucleation does not seem to monopolize all the condensing vapors, probably because the charged particles are not numerous enough. The production of new particles due to ioninduced nucleation (generally smaller) seem to be related to the levels of external radiations. It remains to be seen if the same conclusions apply in other environments.

Acknowledgements. This research was supported by the Academy of Finland Center of Excellence program (project number 1118615) and by the European Commission 6th Framework program project EUCAARI, contract no 036833-2 (EUCAARI) . Veijo Hiltunen and Heikki Laakso are acknowledged for maintenance of the instruments at the SMEAR II station. Petri Keronen is acknowledged for providing the meteorological data. Jussi Paatero, Alessandro 
Franchin, Sigfried Schobesberger, Jukka Pumpanen, Liisa Kulmala and Taina Yli-Juuti are acknowledged for useful discussion and providing supporting data.

Edited by: A. Wiedensohler

\section{References}

Aalto, P., Hämeri, K., Becker, E., Weber, R., Salm, J., Mäkelä, J. M., Hoell, C., O’Dowd, C. D., Karlsson, H., Hansson, H.-C., Väkevä, M., Koponen, I. K., Buzorius, G., and Kulmala, M.: Physical characterization of aerosol particles during nucleation events, Tellus, 53B, 344-358, 2001.

Andreae, M. O. and Rosenfeld, D.: Aerosol-cloud-precipitation interactions. Part 1. The nature and sources of cloud-active aerosols, Earth-Science Reviews, 89, 13-41, 2008.

Birmili, W., Berresheim, H., Plass-Dlmer, C., Elste, T., Gilge, S., Wiedensohler, A., and Uhrner, U.: The Hohenpeissenberg aerosol formation experiment (HAFEX): a long-term study including size-resolved aerosol, $\mathrm{H}_{2} \mathrm{SO}_{4}, \mathrm{OH}$, and monoterpenes measurements, Atmos. Chem. Phys., 3, 361-376, 2003, http://www.atmos-chem-phys.net/3/361/2003/.

Boy, M. and Kulmala, M.: Nucleation events in the continental boundary layer: Influence of physical and meteorological parameters, Atmos. Chem. Phys., 2, 1-16, 2002, http://www.atmos-chem-phys.net/2/1/2002/.

Boy, M., Rannik, Ü., Lehtinen, K. E. J., Tarvainen, V., Hakola, H., and Kulmala, M.: Nucleation events in the continental PBL long term statistical analyses of aerosol relevant characteristics, J. Geophys. Res., 108(D21), 4667, doi:10.1029/2003JD003838, 2003.

Boy, M., Kulmala, M., Ruuskanen, T. M., Pihlatie, M., Reissell, A., Aalto, P. P., Keronen, P., Dal Maso, M., Hellen, H., Hakola, H., Jansson, R., Hanke, M., and Arnold, F.: Sulphuric acid closure and contribution to nucleation mode particle growth, Atmos. Chem. Phys., 5, 863-878, 2005,

http://www.atmos-chem-phys.net/5/863/2005/.

Boy, M., Hellmuth, O., Korhonen, H., Nilsson, E. D., ReVelle, D., Turnipseed, A., Arnold, F., and Kulmala, M.: MALTE - model to predict new aerosol formation in the lower troposphere, Atmos. Chem. Phys., 6, 4499-4517, 2006,

http://www.atmos-chem-phys.net/6/4499/2006/.

Boy, M., Kazil, J., Lovejoy, E. R., Guenther, A., and Kulmala, M.: Relevance of ion-induced nucleation of sulfuric acid and water in the lower troposphere over the boreal forest at northern latitudes, Atmos. Res., 9, 151-158, 2008.

Dal Maso, M., Kulmala, M., Riipinen, I., Wagner, R., Hussein, T., Aalto, P. P., and Lehtinen, K. E. J.: Formation and growth of fresh atmospheric aerosols: Eight years of aerosol size distribution data from SMEAR II, Hyytiälä, Finland. Boreal Environ. Res., 10(5), 323-336, 2005.

Eisele, F., Lovejoy, E. R., Kosciuch, E., Moore, K. F., Mauldin III, R. L., Smith, J. N., McMurry, P. H., and Iida, K.: Negative atmospheric ions and their potential role in ion-induced nucleation, J. Geophys. Res. 111, D04305/04301-D04305/04311, doi:10.1029/2005JD006568, 2006.

Gagné, S., Laakso, L., Petäjä, T., Kerminen, V.-M., and Kulmala, M.: Analysis of one year of Ion-DMPS data from the SMEAR II station, Finland, Tellus, 60B, 318-329, 2008.
Hari, P. and Kulmala, M.: Station for measuring ecosystematmosphere relations (SMEAR II), Boreal Env. Res., 10(5), 315$322,2005$.

Hatakka, J., Paatero, J., Viisanen, Y., and Mattsson, R.: Variations of external radiation due to meteorological and hydrological factors in central Finland, Radiochemistry, 40(6), 534-538, 1998.

Hirsikko, A., Laakso, L., Hõrrak, U., Aalto, P. P., Kerminen, V.M., and Kulmala, M.: Annual and size dependent variation of growth rates and ion concentrations in boreal forest, Boreal Env. Res., 10, 357-369, 2005.

Hoppel, W. A.: Determination of the aerosol size distribution from the mobility distribution of the charged fraction of aerosols, J. Aerosol Sci., 9, 41-54, 1978.

Iida, K., Stolzenburg, M., McMurry, P. H., Dunn, M., Smith, J., Eisele, F., and Keady, P.: Contribution of ion-induced nucleation to new particle formation: Methodology and its application to atmospheric observations in Boulder, Colorado, J. Geophys. Res., 111, D23201, doi:10.1029/2006JD007167, 2006.

Iida, K., Stolzenburg, M. R., McMurry, P. H., and Smith, J. N.: Estimating nanoparticle growth rates from sizedependent charged fractions: Analysis of new particle formation events in Mexico City, J. Geophys. Res., 113, D05207, doi:10.1029/2007JD009260, 2008.

Kerminen, V.-M., Anttila, T., Petäjä, T., Laakso, L., Gagné, S., Lehtinen, K. E. J., and Kulmala, M.: Charging state of the atmospheric nucleation mode: Implications for separating neutral and ion-induced nucleation, J. Geophys. Res., 112, D21205, doi:10.1029/2007JD008649, 2007.

Kuang, C., McMurry, P. H., McCormick, A. V., and Eisele, F. L.: Dependence of nucleation rates on sulfuric acid vapor concentration in diverse atmospheric locations, J. Geophys. Res., 113, D10209, doi:10.1029/2007JD009253, 2008.

Kulmala, M., Dal Maso, M., Mäkelä, J., Pirjola, L., Väkevä, M., Aalto, P., Miikkulainen, P., Hämeri, K., and O'Dowd, C. D.: On the formation, growth and composition of nucleation mode particles, Tellus 53B, 479-490, 2001.

Kulmala, M.: How particles nucleate and grow, Science, 302, 1000-1001, 2003.

Kulmala, M., Vehkamäki, H., Petäjä, T., Dal Maso, M., Lauri, A., Kerminen, V.-M., Birmili, W., and McMurry, P. H.: Formation and growth rates of ultrafine atmospheric particles: a review of observations, J. Aerosol Sci., 35, 143-176, 2004.

Kulmala, M., Lehtinen, K. E. J., and Laaksonen, A.: Cluster activation theory as an explanation of the linear dependence between formation rate of $3 \mathrm{~nm}$ particles and sulphuric acid concentration, Atmos. Chem. Phys., 6, 787-793, 2006, http://www.atmos-chem-phys.net/6/787/2006/.

Kulmala, M., Riipinen, I., Sipilä, M., Manninen, H. E., Petäjä, T. Junninen, H., Dal Maso, M., Mordas, G., Mirme, A., Vana, M., Hirsikko, A., Laakso, L., Harrison, R. M., Hanson, I., Leung, C., Lehtinen, K. E. J., Kerminen, V.-M.: Toward direct measurement of atmospheric nucleation, Science, 318, 89-92, 2007a.

Kulmala, M., Mordas, G., Petäjä, T., Grönholm, T., Aalto, P. P., Vehkamäki, H., Hienola, A. I., Herrmann, E., Sipilä, M., Riipinen, I., Manninen, H. E., Hämeri, K., Stratmann, F., Bilde, M., Winkler, P. M., Birmili, W. and Wagner, P. E.: The condensation particle counter battery (CPCB): A new tool to investigate the activation properties of nanoparticles, J. Aerosol Sci., 38, 289-304, 2007b. 
Kulmala, M. and Kerminen, V.-M.: On the formation and growth of atmospheric nanoparticles, Atmos. Res., 90, 132-150, 2008.

Kurtén, T., Noppel, M., Vehkamäki, H., Salonen, M., and Kulmala, M.: Quantum chemical studies of hydrate formation of $\mathrm{H}_{2} \mathrm{SO}_{4}$ and $\mathrm{HSO}_{4}^{-}$, Boreal Environ. Res., 12, 421-430, 2007.

Kurtén, T., Loukonen, V., Vehkamäki, H., and Kulmala, M.: Amines are likely to enhance neutral and ion-induced sulfuric acid-water nucleation in the atmosphere more effectively than ammonia, Atmos. Chem. Phys., 8, 4095-4103, 2008, http://www.atmos-chem-phys.net/8/4095/2008/.

Kurtén, T., Ortega, I. K., and Vehkamäki, H.: The sign preference in sulfuric acid nucleation, Journal of Molecular Structure: THEOCHEM, 901, 169-173, 2009.

Laakso, L., Petäjä, T., Lehtinen, K. E. J., Kulmala, M., Paatero, J., Hõrrak, U., Tammet, H., and Joutsensaari, J.: Ion production rate in a boreal forest based on ion, particle and radiation measurements, Atmos. Chem. Phys., 4, 1933-1943, 2004,

http://www.atmos-chem-phys.net/4/1933/2004/.

Laakso, L., Gagné, S., Petäjä, T., Hirsikko, A., Aalto, P. P., Kulmala, M., and Kerminen, V.-M.: Detecting charging state of ultra-fine particles: instrumental development and ambient measurements, Atmos. Chem. Phys., 7, 1333-1345, 2007, http://www.atmos-chem-phys.net/7/1333/2007/.

Laakso, L., Gronholm, T., Kulmala, L., Haapanala, S., Hirsikko, A., Lovejoy, ER., Kazil, J, Kurten, T., Boy, M., Nilsson, E. D., Sogachev, A., Riipinen, I., Stratmann, F., and Kulmala, M.: Hotair balloon as a platform for boundary layer profile measurements during particle formation, Boreal Environ. Res., 12(3), 279-294, $2007 b$.

Lohmann, U. and Feichter, J.: Global indirect aerosol effects: a review, Atmos. Chem. Phys., 5, 715-737, 2005, http://www.atmos-chem-phys.net/5/715/2005/.

Lovejoy, E. R., Curtius, J., and Froyd, K. D.: Atmospheric ioninduced nucleation of sulfuric acid and water, J. Geophys. Res., 109, D08204, doi:10.1029/2003JD004460, 2004.

Mäkelä, J. M., Riihelä, M., Ukkonen, A., Jokinen, V., and Keskinen, J.: Comparison of mobility equivalent diameter with KelvinThomson diameter using ion mobility data, J. Chem. Phys., 105, 1562-1571, 1996.

Mäkelä, J. M., Salm, J., Smirnov, V. V., Koponen, I., Paatero, J., and Pronin, A. A.: Electrical charging state of fine and ultrafine particles in boreal forest air, J. Aerosol Sci., 32, 149-150, 2003.

Manninen, H. E., Nieminen, T., Riipinen, I., Yli-Juuti, T., Gagné, S., Asmi, E., Aalto, P. P., Petäjä, T., Kerminen, V.-M., and Kulmala, M.: Charged and total particle formation and growth rates during EUCAARI 2007 campaign in Hyytiälä, Atmos. Chem. Phys., 9, 4077-4089, 2009,

http://www.atmos-chem-phys.net/9/4077/2009/.

Manninen, H. E., Petäjä, T., Asmi, E., Riipinen, I., Nieminen, T., Mikkilä, J., Hõrrak, U., Mirme, A., Mirme, S., Laakso, L., Kerminen, V.-M., and Kulmala, M.: Long-term field measurements of charged and neutral clusters using Neutral cluster and Air Ion Spectrometer (NAIS), Boreal Env. Res, 14, 591-605, 2009b.

Merikanto, J., Spracklen, D. V., Mann, G. W., Pickering, S. J., and Carslaw, K. S.: Impact of nucleation on global CCN, Atmos. Chem. Phys., 9, 8601-8616, 2009,

http://www.atmos-chem-phys.net/9/8601/2009/.

Mertes, S., Schröder, F., and Wiedensohler, A.: The particle detection efficiency curve of the TSI-3010 CPC as a function of temperature difference between saturator and condenser, Aerosol Sci. Technol., 23, 257-261, 1995.

Mirme, A., Tamm, E., Mordas, G., Vana, M., Uin, J., Mirme, S., Bernotas, T., Laksso, L., Hirsikko, A., and Kulmala, M.: A widerange multi-channel Air Ion Spectrometer, Boreal Env. Res., 12, 247-264, 2007.

Mirme, S., Mirme, A., Minikin, A., Petzold, A., Hõrrak, U., Kerminen, V.-M., and Kulmala, M.: Atmospheric sub-3 nm particles at high altitudes, Atmos. Chem. Phys., 10, 437-451, 2010,

http://www.atmos-chem-phys.net/10/437/2010/.

Myhre, G., Berglen, T. F., Johnsrud, M., Hoyle, C. R., Berntsen, T. K., Christopher, S. A., Fahey, D. W., Isaksen, I. S. A., Jones, T. A., Kahn, R. A., Loeb, N., Quinn, P., Remer, L., Schwarz, J. P., and Yttri, K. E.: Modelled radiative forcing of the direct aerosol effect with multi-observation evaluation, Atmos. Chem. Phys., 9, 1365-1392, 2009, http://www.atmos-chem-phys.net/9/1365/2009/.

Nieminen, T., Manninen, H. E., Sihto, S.-L., Yli-Juuti, T., Mauldin III, R. L., Petäjä, T., Riipinen, I., Kerminen, V.-M., and Kulmala, M.: Connection of Sulfuric Acid to Atmospheric Nucleation in Boreal Forest, Environ. Sci. Technol., 43, 4715-4721, 2009.

Nilsson, E. D., Rannik, U., Kulmala, M., Buzorius, G., and O'Dowd, C. D.: Effect of the continental boundary layer evolution, convection, turbulence and entrainment on aerosol formation, Tellus, 53B, 441-461, 2001.

Paatero, J., Hatakka, J., and Viisanen, Y.: Concurrent Measurements of Airborne Radon-222, Lead-210 and Beryllium-7 at the Pallas-Sodankylä GAW Station, Northern Finland. Tech. rep., Finnish Meteorological Institute, 1998.

Riipinen, I., Sihto, S.-L., Kulmala, M., Arnold, F., Dal Maso, M., Birmili, W., Saarnio, K., Teinilä, K., Kerminen, V.-M., Laaksonen, A., and Lehtinen, K. E. J.: Connections between atmospheric sulphuric acid and new particle formation during QUEST III-IV campaigns in Heidelberg and Hyytiälä, Atmos. Chem. Phys., 7, 1899-1914, 2007,

http://www.atmos-chem-phys.net/7/1899/2007/.

Sogachev, A. and Panferov, O.: Modification of two-equation models to account for plant drag, Bound. Lay. Meteorol., 121, 229266, 2006.

Stanier, C. O., Khlystov, A. Y., and Pandis, S. N.: Nucleation events during the Pittsburgh Air Quality Study: Description and relation to key meteorological, gas phase, and aerosol parameters, Aerosol Sci. Technol., 38, 253-264, 2004.

Stolzenburg, M. R. and McMurry, P. H.: An ultrafine aerosol condensation nucleus counter, Aerosol Sci. Technol., 14, 48-65, 1991.

Spracklen, D. V., Carslaw, K. S., Kulmala, M., Kerminen, V.-M., Sihto, S.-L., Riipinen, I., Merikanto, J., Mann, G. W., Chipperfield, M. P., Wiedensohler, A., Birmili, W., and Lihavainen, H.: Contribution of particle formation to global cloud condensation nuclei concentrations, Geophys. Res. Lett., 35, L06808, doi:10.1029/2007GL033038, 2008.

Stevens, B. and Feingold, G.: Untangling aerosol effects on clouds and precipitation in a buffered system, Nature, 461, 607-613, doi:10.1038/nature08281, 2009.

Tammet, H.: Size and mobility of nanometer particles, clusters and ions, J. Aerosol Sci., 26, 459-475., 1995.

Tammet, H.: Reduction of air ion mobility to standard conditions, J. Geophys. Res.-Atmos., 103, 13933-13937, 1998. 
Tammet, H.: Continuous scanning of the mobility and size distribution of charged clusters and particles in atmospheric air and the balanced scanning mobility analyzer BSMA, Atmos. Res., 82, 523-535, 2006.

Twomey, S.: Aerosols, clouds and radiation, Atmos. Environ., 25A, 2435-2442, 1991.

Vana, M., Tamm, E., Hõrrak, U., Mirme, A., Tammet, H., Laakso, L., Aalto, P., and Kulmala, M.: Charging state of atmospheric nanoparticles during the nucleation burst events, Atmos. Res., 82, 536-546, 2006.

Vehkamäki, H., Dal Maso, M., Hussein, T., Flanagan, R., Hyvärinen, A., Lauros, J., Merikanto, P., Mönkkönen, M., Pihlatie, K., Salminen, K., Sogacheva, L., Thum, T., Ruuskanen, T. M., Keronen, P., Aalto, P. P., Hari, P., Lehtinen, K. E. J., Rannik, $\ddot{U}$, and Kulmala, M.: Atmospheric particle formation events at Värriö measurement station in Finnish Lapland 1998-2002, Atmos. Chem. Phys., 4, 2015-2023, 2004, http://www.atmos-chem-phys.net/4/2015/2004/.

Vesala, T., Haataja, J., Aalto, P., Altimir, N., Buzorius, G., Garam, E., Hämeri, K., Ilvesniemi, H., Jokinen, V., Keronen, P., Lahti, T., Markkanen, T., Mäkelä, J., Nikinmaa, E., Palmroth, S., Palva, L., Pohja, T., Pumpanen, J., Rannik, Ü., Siivola, E., Ylitalo, H., Hari, P., and Kulmala, M.: Long-term field measurements of atmosphere-surface interactions in boreal forest combining forest ecology, micrometeorology, aerosol physics and atmospheric chemistry, Trends in Heat, Mass and Momentum Transfer, 4, 1735, 1998.
Weber, R. J., Marti, J. J., McMurry, P. H., Eisele, F. L., Tanner, D. J. and Jefferson, A.: Measured atmospheric new particle formation rates: implications for nucleation mechanisms, Chem. Eng. Commun., 151, 53-64, 1996.

Winkler, P. M., Steiner, G., Virtala, A., Vehkamäki, H., Noppel, M., Lehtinen, K. E. J., Reischl, G. P.,Wagner, P. E., and Kulmala, M.: Heterogeneous Nucleation Experiments Bridging the Scale from Molecular Ion Clusters to Nanoparticles, Science, 319, 1374 , doi:10.1126/science. 1149034, 2008.

Winklmayr, W., Reischl, G., Lindner, A., and Berner, A.: A new electromobility spectrometer for the measurement of aerosol size distributions in the size range from 1 to $1000 \mathrm{~nm}$, J. Aerosol Sci., 22, 289-296, 1991.

Yu, F. and Turco, R.: From molecular clusters to nanoparticles: role of ambient ionization in tropospheric aerosol formation, J. Geophys. Res., 106, 4797-4817, 2001.

Yu, F. and Turco, R.: Case studies of particle formation events observed in boreal forests: implications for nucleation mechanisms, Atmos. Chem. Phys., 8, 6085-6102, 2008, http://www.atmos-chem-phys.net/8/6085/2008/. 